\title{
境界埋め込み法を取り入れたLESIよる \\ 開水路栈粗度乱流場の上昇剥離渦の解析 \\ ANALYSIS OF ASCENDING SEPATARED VORTICES GENERATED FROM A STRIP ROUGHNESS BY USING LES WITH IMMERSED BOUNDARY METHOD
}

\author{
吉村英人 1 ・藤田一郎 2 \\ Hideto YOSHIMURAE and Ichiro FUJITA \\ 1学生会員 神戸大学大学院 自然科学研究科博士課程前期課程（干657-8501 神戸市灘区六甲台町1-1） \\ 2正会員 学術博 神戸大学教授 工学部建設学科（干657-8501 神戸市灘区六甲台町1-1）
}

\begin{abstract}
A large eddy simulation (LES) of turbulent open-channel flow with strip roughness is performed together with the image analysis by the particle image velocimetry (PIV). In the simulation, an immersed boundary method is introduced in order to be able to simulate arbitrary channel bed topography. In addition, we used a sophisticated LES model to simulate the flow near the complicated boundary without using a damping function. The hydraulic conditions for the simulation and the experiment are restricted to a relatively small Froude number (Fr) flow, e.g. Fr less than 0.25 , in order not to generate appreciable water surface fluctuation. The results show favorable agreements regarding the statistical properties such as the mean and the Reynolds stress distributions. Additionally, the instantaneous flow structure at the instance when a separation vortex hit the water surface is investigated, showing that the separated vortex ascends up to the water surface and locally decelerate the convection velocity of the surface profile.
\end{abstract}

Key Words : LES, strip roughness, open-channel turbulence, PIV, immersed boundary method, separation vortex

\section{1. まえがき}

河川の表面は様々な物理的作用を受けて多種多様な変 化を示す. それらの変化を与える要因の一つに風の影響 があるが，無風状態でも水面が大きな変動を示す場合が あるのは周知のことである. 例えば, レイノルズ数の増 大に伴う流体内部の乱れの増幅による水面の変動, 河床 面で発生する乱流渦の水面との衝突による水面の変動, あるいは田を有する河岸から発生する波の影響による 水面変動などがそうである. 実際の河川で見られるのは これら複数の要因に基づく変動が重畳したものと考えら れる. 水面近傍の流れ場はミクロ的に見れば気液界面の 現象 ${ }^{1,2)}$ を解明する点で重要であるが，水面変動をマク ロ的に見た場合には面的な幾何学パターンが表面流と何 らかの相関を持って移流することが考えられることから， 表面流速分布を計測するための事象としても利用価值が ある3,4,5)

一方, 乱流場の三次元解析手法は近年著しい発達を遂 げ，RANSモデルに加えてDNSやLESによる解析が一般
的に行われるようになってきたのは周知のことである 6),7). しかしながら，大半の解析は滑面境界を有する流 れ場を対象としたものであり, 粗度のある流れ場を詳細 に数值解析した研究例は少ない. 自由水面を有する流れ 場を対象とした解析もこれまで数多く行われているが, 粗度のある流れや水面変動の大きな流れ場を対象とした 研究例は多くない ${ }^{8), 9)}$. 少なくとも粗度がある流れ場の LES解析においては, 水面近傍の流れ場や水面変動を対 象とした研究例はほとんどなく, 現象論的にも十分な整 理がされていないのが現状と思われる. そこで，本研究 では水面変動の要因として河床面起因の剥離渦と水表面 流場の関係に着目し，LESおよび可視化画像解析(PIV) による検討を行う。本報では粗度要素を有する流れ場の 基本的な特性を調べるために，比較的フルード数が低く $(\mathrm{Fr}=0.25)$, 顕著な水面変動の発生が予想されない開水 路の流れ場に，正方形断面を持つ栈粗度を配置したケー スを対象として検討を進める。

\section{2. 可視化実験の概要}


表-1 水理条件

\begin{tabular}{|l|c|c|}
\hline & Ls05 & Ls10 \\
\hline 水深 $: h_{l}(\mathrm{~cm})$ & \multicolumn{2}{|c|}{4.0} \\
\hline 平均流速 $: U_{m}(\mathrm{~cm} / \mathrm{s})$ & \multicolumn{2}{|c|}{15.6} \\
\hline 相対粗度間隔 $: L k$ & 5 & 10 \\
\hline フルード数 $: F r$ & \multicolumn{2}{|c|}{0.25} \\
\hline レイノルズ数 $: R e$ & \multicolumn{2}{|c|}{6240} \\
\hline 水路床勾配 $: I$ & \multicolumn{2}{|c|}{$1 / 500$} \\
\hline
\end{tabular}

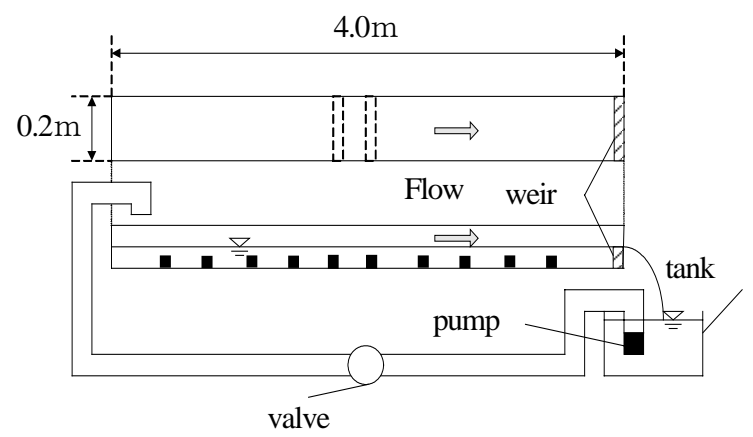

図-1 実験装置

\section{（1）実験装置}

実験には図-1に示寸，水路長 $4.0 \mathrm{~m}$, 水路幅 $0.2 \mathrm{~m}$ のア クリル製の直線開水路を用いた。栈粗度には高さ $d=0.9 \mathrm{~cm}$, 幅 $k=0.9 \mathrm{~cm}$ のアルミニウム製の正方形栈粗度 を用い，栈粗度は水路上流から下流まで等間隔に配置し た. 流れの可視化には粒径 $10 \mu \mathrm{m}$ のナイロン破砕トレー サーを用い，水路下方よりアルゴンイオンレーザによる レーザシートで照射して得られる流れの鉛直断面を高速 ビデオカメラ (110fps) で撮影しPIVにより解析を行った。

\section{（2）水理条件}

今回行った実験での水理条件を表-1に示す．水深は $4 \mathrm{~cm}$ に固定しフルード数は 0.25 と水面変動の小さい比較 的穏やかな流れを対象とした．ただし，粗度要素上の局 所的なフルード数は 0.37 となる. 粗度間隔は相対粗度間 隔を $L k=5$ および10の 2 通りとした。ここでLは粗度の中 心間隔である. 粗度間隔が5の場合のケース名をLs05, 10の場合をLs10とした.

\section{3. 数値計算概要}

\section{（1）基礎方程式}

数值計算は直交格子におけるLESで行った. フィルタ 操作を施した非圧縮性流れの連続の式およびN-S方程式 を以下に示寸. なおN-S方程式は時間的に前進差分した 形で示す.

$$
\frac{\partial \bar{u}_{i}}{\partial x_{i}}=0
$$

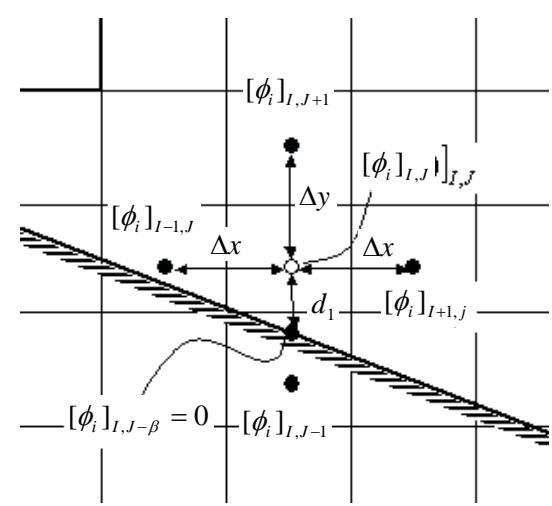

図-2 境界埋め込み法の速度の補間図

$$
\begin{aligned}
\frac{\bar{u}_{i}^{n+1}-\bar{u}_{i}^{n}}{\Delta t} & =-\frac{1}{\rho} \frac{\partial \bar{p}}{\partial x_{i}}-\bar{u}_{j} \frac{\partial \bar{u}_{i}}{\partial x_{j}} \\
& +\frac{\partial}{\partial x_{i}}\left\{v_{t}\left(\frac{\partial \bar{u}_{i}}{\partial x_{j}}+\frac{\partial \bar{u}_{j}}{\partial x_{i}}\right)\right\}+v \frac{\partial^{2} \bar{u}_{i}}{\partial x_{j}^{2}}+f_{i}
\end{aligned}
$$

ここに, $x_{i}: i$ 方向座標 $(i=1,2,3), \overline{u_{i}}$ : グリッド成分 の $i$ 方向速度, $v$ : 動粘性係数, $v_{t}$ : 渦動粘性係数, $f_{i}:$ グリッド成分の $i$ 方向外力である.

\section{（2）境界埋め込み法 (IBM: Immersed Boundary Method)}

実河川における河床面は砂䃋で構成された粗面であり， 河床波が発生すればさらに河床面の形状は複雑となる. このように複雑な境界形状を有する実際河川の流れ場の 詳細を検討するためには，ある程度の自由度を持って境 界形状を定義できることが重要である，そこで，本研究 では今後様々な底面形状に対する数值計算を行っていく ことを視野に入れ，直交格子座標系において任意形状の 物体の影響を取り入れることができる境界埋め込み法を 前述のLESの解析プログラムに導入することとした．境

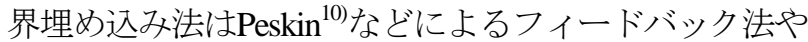
Mohd-Yusof ${ }^{11}$ による直接強制法が開発されているが，本 研究では計算が簡易でかつ安定性の高い直接強制法を用 いることにした．境界埋め込み法は壁面境界を外力の形 で表現するものであり，壁面近傍および壁面内部の格子 点においては外力項が加えられる. その外力項 $f$ え下 の式で表される.

$$
f_{i}=-R H S+\frac{U_{i}^{n+1}-\bar{u}_{i}^{n}}{\Delta t}
$$

ここでRHSは式(2)の右辺第1項から第4項の和である. $U_{i}^{n+1}$ はそその隣接格子点での速度と壁面上のゼロ速度を 補間することによって与える境界速度であり，壁面内部 では $U_{i}^{n+1}=0$ とする. 境界面における速度の補間方法に は図-2に示寸ように多方向線形補間を用いた．多方向線 形補間は壁面最近傍格子点に隣接する6点の速度を用い るもので隣接する格子点が存在する場合にはその点での 速度を用い，格子点よりも手前に壁面が存在する場合に 


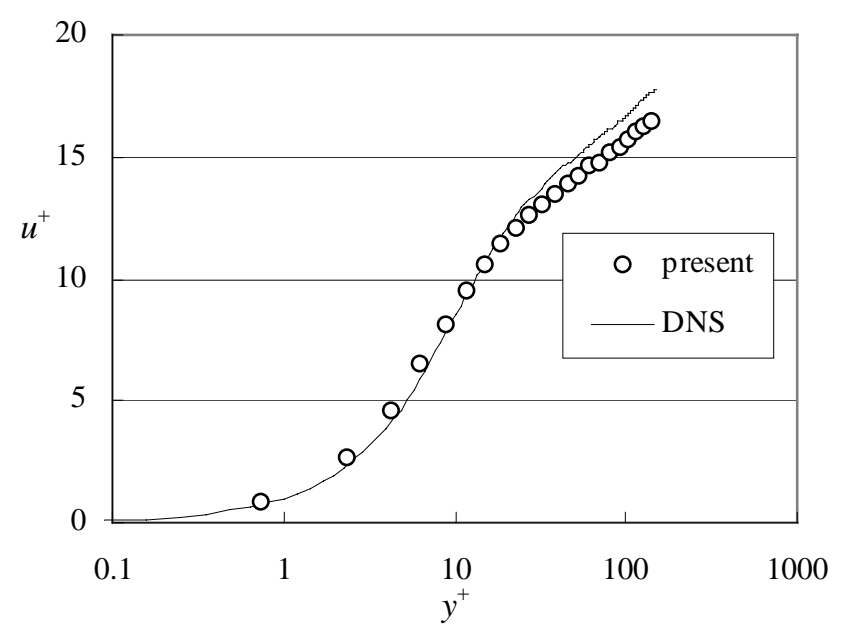

図-3 主流方向平均流速分布

は壁面でのゼロ速度を用い距離による重み付けで補間を 行う.

\section{(3) MTS SGSモデル}

LESにおける渦動粘性係数の算出において，従来の標 準Smagorinskyモデルを用いると壁面近傍で適切なダン ピング関数を乗じなければならないことや，モデル係数 を流れ場によって変化させなければならないことなどか ら，流れの場の局所性を反映することはできない. また， 底面形状が複雑になれば, 壁面からの距離の定義も煩雑 となるため, 標準Smagorinskyモデルの適用はさらに困 難となる.これらの問題を解決するモデルとして Germanoら ${ }^{12)}$ によって開発されたDynamic SGSモデルが あるが計算不安定に陷りやすい.

そこで，本研究では稲垣らによって開発されたMTS SGSモデル13)を用いることとした. このMTS SGSモデル は，時間スケールとして乱れのSGS成分のもつ時間ス ケールと歪み速度の大きさから与えられる時間スケール との調和平均を用いることにより，壁面近傍で自動的に ダンピングがかかる効果を取り入れることができる。ま た，計算安定性も高い. MTS SGSモデルによる渦動粘 性係数 $v_{t}$ は以下の式で表される.

$$
\begin{gathered}
k_{e s}=\left(\bar{u}_{k}-\hat{\bar{u}}_{k}\right)^{2} \\
T_{s}^{-1}=\left(\frac{\bar{\Delta}}{\sqrt{k_{e s}}}\right)^{-1}+\left(\frac{C_{T}}{|\bar{S}|}\right)^{-1} \\
v_{t}=C_{M T S} k_{e s} T_{s}
\end{gathered}
$$

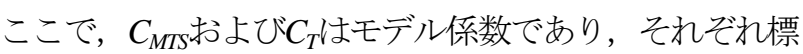
準值である $0.05 ， 10$ をえる。历はフィルタ幅で $\bar{\Delta}=(\Delta x \Delta y \Delta z)^{1 / 3}$ とした. $|\bar{S}|$ はグリッドスケールの 歪み速度テンソルの大きさ, また， $\hat{\bar{u}}_{k}$ はグリッド成分 として計算される流速成分にフィルタリング操作を行う ことを意味し，ここでは稲垣らと同様にSimpson則を適 用した. なお，添字の $k$ は各方向を示す指数である.

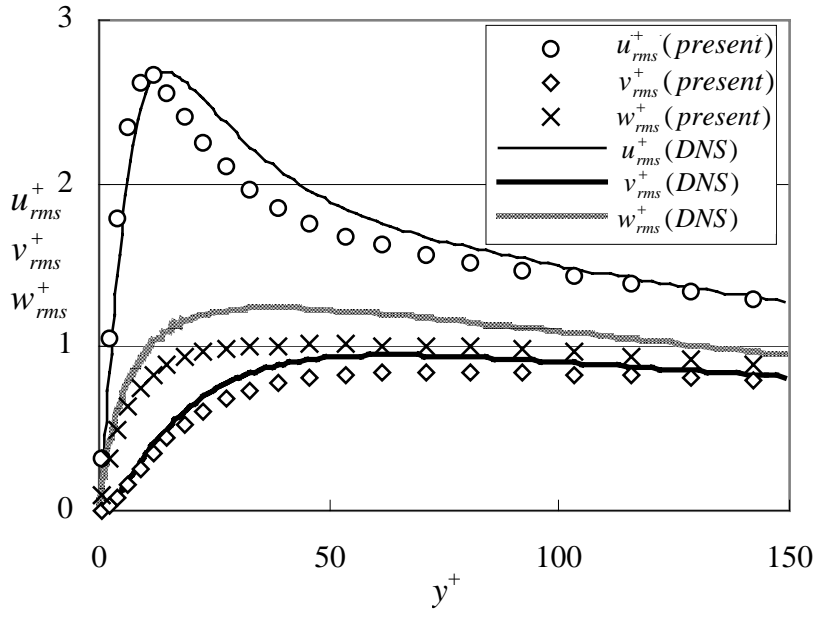

図-4 各方向乱れ強度分布

\section{（4）計算条件}

計算領域は，主流方向 $x$, 壁垂直方向 $y$ ，およびスパン 方向 $z$ にそれぞれ $(9 H, H, H)$ とし, 主流方向に周期境界条 件を適用することで等間隔に並んだ栈粗度の流れ場を再 現した. ここで，Hは平均水深を表す．格子数はそれぞ れ $(180,48,48)$ とし， $z$ 方向には等間隔格子を用い， $x$ 方向 およびy方向にはtanh関数で粗密をつけた不等間隔格子 を用いた. 主流方向およびスパン方向には周期境界条件, 上部境界にはすべり条件, 底面境界にはすべりなし条件 を適用した. 今回は実験で行ったフルード数 0.25 , 相対 粗度間隔 $L k=10$ のケースをシミュレーションの対象とし た. なお時間の離散化にはFractional Step法を，移流項の 離散化には梶島の対流型補間法 ${ }^{14)}$ を用い，時間差分ス キームには 2 次精度のAdams-Bashforth法, 分子粘性項 にはCrank-Nicolson法を用いた。また，無次元時間刻み $\Delta t=5.0 \times 10^{-4}$ で計算を行った.

\section{4. 解析結果}

\section{（1）境界埋め込み法およびMTSのチャンネル乱流での精 度検証}

境界埋め込み法およびMTSモデルの精度検証のため にチャンネル乱流での計算を行った。計算領域を，主流 方向 $x$ ，壁垂直方向 $y$ ，およびスパン方向 $z$ にそれぞれ $(3.84 H, H, 1.92 H)$, 格子数はそれぞれ $(48,48,48)$ とし, $x$ 方 向およびz方向には等間隔格子を用い, $y$ 方向にはtanh関 数で粗密をつけた不等間隔格子を用いた。 Hはチャンネ ル高さを示す. 主流方向およびスパン方向には周期境界 条件，上部と下部の壁面境界には境界埋め込み法により すべりなし条件を適用した. 摩擦レイノルズ数 $R e_{i}=300$ とし一定の圧力勾配を加えて流れを駆動させた. 十分に 流れを発達させて得られた統計量をDNS ${ }^{15)}$ の結果と比較 する. 図-3に流れ方向の平均流速分布を, 図-4に各方向 速度成分 $u, v, w$ それぞれの乱れ強度を示す. 平均流速 分布, 乱れ強度ともDNSの結果との対応は概ね良好で 


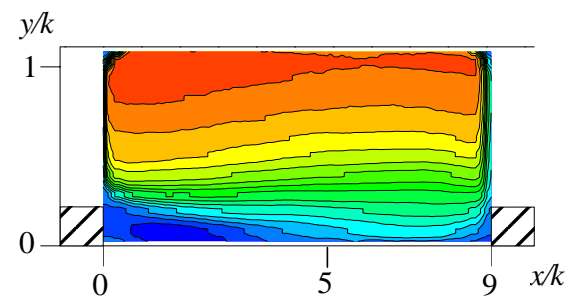

(a) Exp.

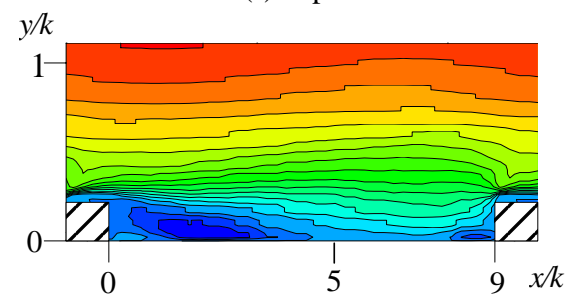

(b) Calc.

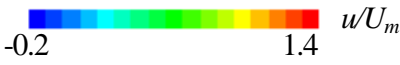

図-5 平均流速分布(Ls10)

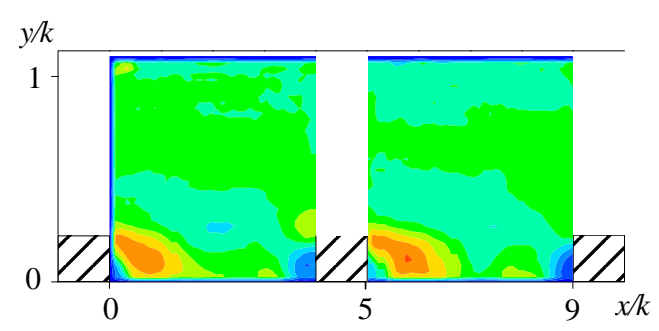

(a) $\mathrm{Ls} 05$

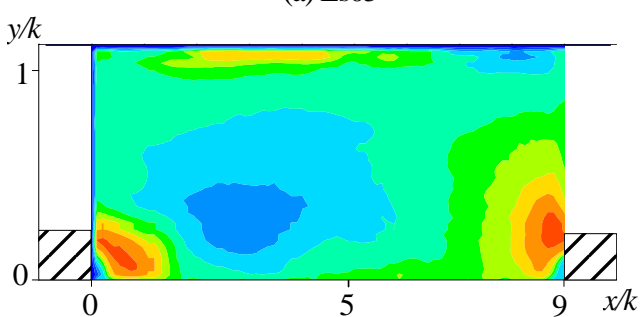

(b) Ls10

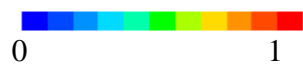

図-7 上昇流 $(\mathrm{v}>0)$ の発生頻度分布 (Exp.)

あることがわかり，MTSおよび境界埋め込み法の導入 が有効であることがわかる.

\section{（2）平均流速分布およびレイノルズ応力分布の比較}

次に栈粗度の流れ場の解析結果を示寸。まず，図-5に Ls10のケースの平均流速分布図を示す. PIVとLESによ る全体的な平均流速分布の一致は良好であることがわか る. 特に, $x / k=5.0$ 付近での再付着あるいは粗度間で発生 する再循環渦がLESでも再現できている. また，ここで は示さないが他のケースにおいても良好な結果が得られ ている. 次にレイノルズ応力分布を図-6に示す. Ls05, Ls10両ケースともLESの方が少し大きめにでている所が あるものの, どちらも粗度高さにおける自由せん断層で 最大值を示すなど，分布形状はよく一致している.

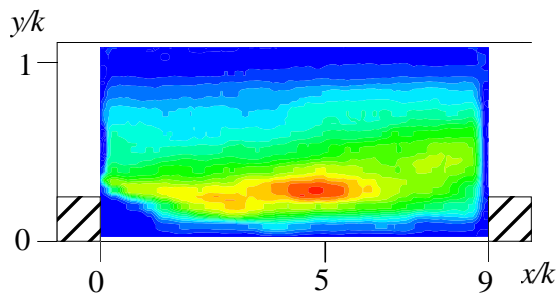

(a) Exp.

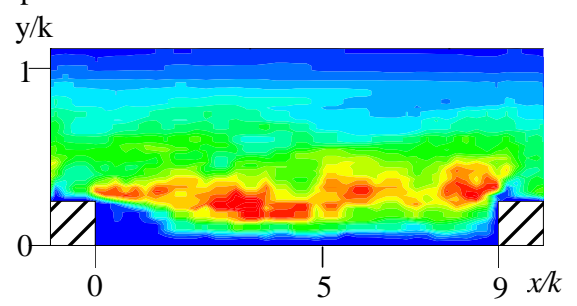

(b) Calc.

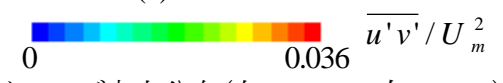

図-6 レイノルズ応力分布(左 : Ls05 右 : Ls10)

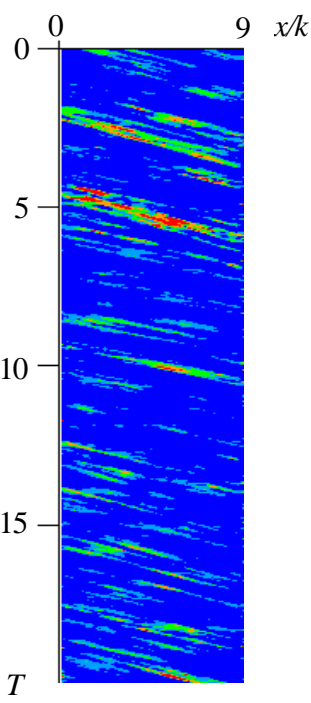

(a) Exp.

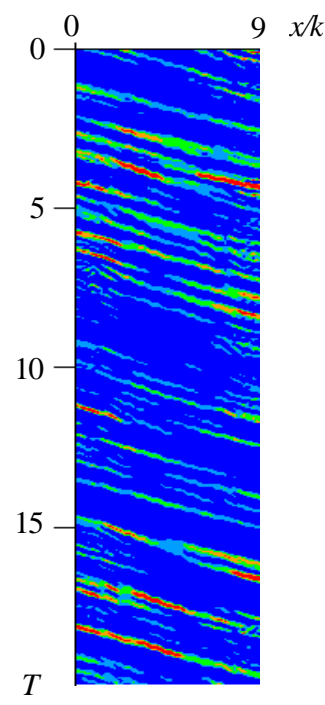

(b) Calc.

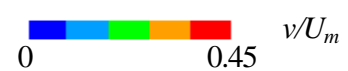

図-8 水面付近における流速鉛直成分の時空間プロット

$$
\left(T=t U_{m}, h_{l}\right)
$$

ただし，このレイノルズ応力分布図からもわかるように， 粗度要素から水面に向かって放出されると考えられる剥 離渦による影響は時間平均された統計量の分布には現わ れていない.

\section{（3）上昇流の発生頻度}

平均的な流れ場を見るだけでは間欠的に発生する剥離 渦などの上昇流の特性を捉えることはできない，そこで， ここでは速度の鈆直成分に注目し，得られた全時系列 データから $v>0$ となる発生頻度を求めた，得られた分布 図を図-7に示す。まず, Ls05, Ls10のどちらとも上流側 栈粗度後部で頻度が高くなっていることがわかる。これ は，栈粗度間で発生する循環渦内の上向きの成分による ものである.また，下流側の栈粗度付近に着目すると， 


\section{1}

$z / k$

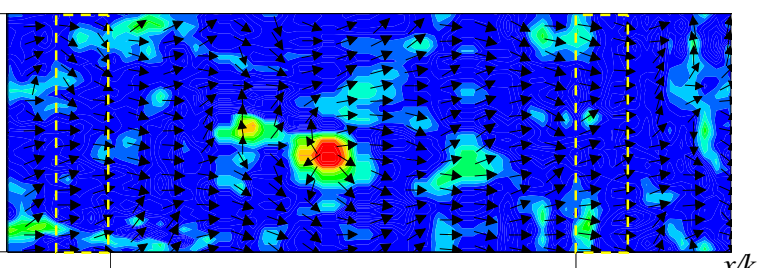

0

9

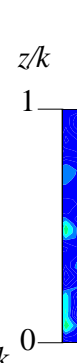
水面付近での正の発散值と平均流速で動く移動座標系から見た流速ベクトル $\overrightarrow{0.5} u_{s} / U_{m} \square \operatorname{div} \cdot H / U m$

$0 \quad 5.0$

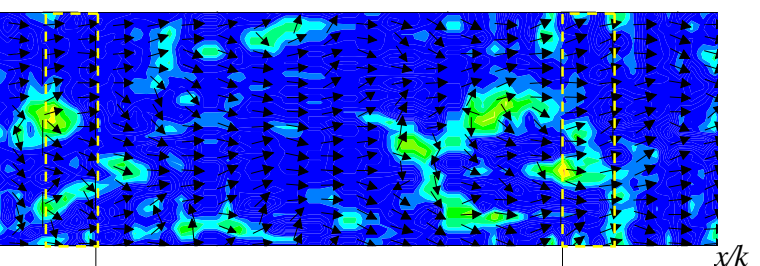

9
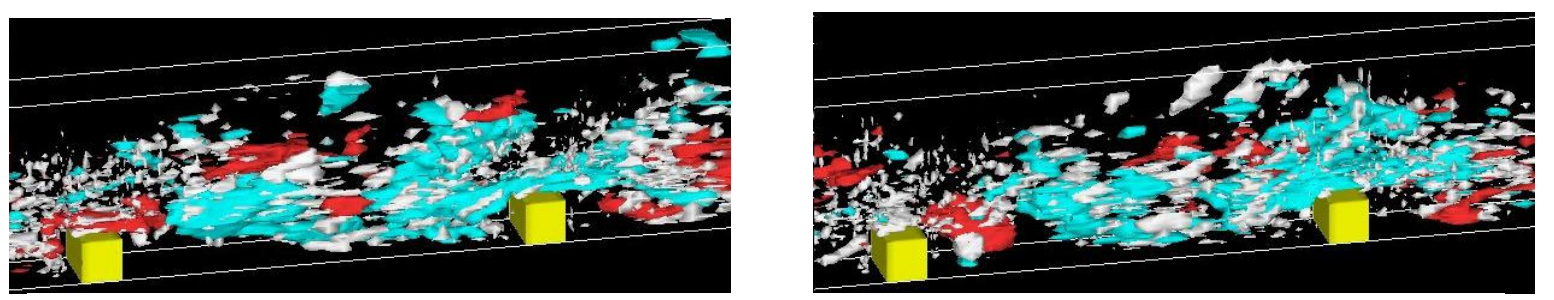

速度 $u$ 成分 (白 : 速度勾配テンソルの第二不変量 $Q=10$ の領域 赤 : 高速領域 青 : 低速領域)
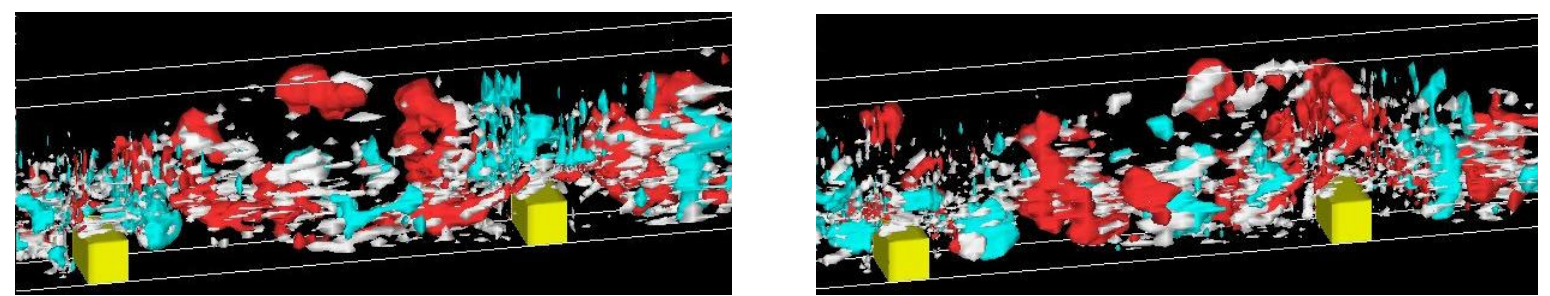

速度 $v$ 成分 (白 : 速度勾配テンソルの第二不変量 $Q=10$ の領域 赤 : 上昇流領域 青 : 下降流領域)

$T=0$

$T=0.5$

図-9 三次元流れ場の可視化 $\left(T=t U_{m} / h_{1}\right)$

上昇流の発生頻度はLs05ではあまり高くないのに対して， Ls10のケースは高い值を示している. これはLs10では栈 栈粗度から剥離した流れが栈粗度間に再付着しそこから 発生する上昇流や栈粗度を乗り越える流れによるもので あると思われる. 一方Ls05では流れが再付着せずに栈粗 度間での流れは単なる循環流となっているために，主流 域にその影響が及ぶような上昇流はあまり見られない。 一方, 水面付近の上昇流の特徵に注目してみると, 特に Ls10の場合に粗度要素の中間付近の水面近傍で発生頻度 の局所的な増大が確認できる.これらは, 粗度要素に よって上向きに流向が変化した剥離上昇流の影響が水面 に達したことを示しているものと考えられる. 以上のよ うに, 栈粗度流れにおける上昇流の発生は, 粗度間に再 付着点がある場合 (Ls10)の方が大きく, 再付着点の存在 が流れの鉛直方向の変動に重要な役割を果たしているも のと思われる.

\section{（4）水面付近での鉛直方向速度成分}

水路底面で発生した剥離渦の一部は継続的に上昇し, 水面に到達する.この状況を確認するために, PIVでは水 面に最も近い高さ $\left(y / h_{l}=0.9\right)$, LESでは上面のすべり面付近 の高さ $(y / H=0.98)$ における鉛直流速成分の時間変動を調心 た. ここでは, 時空間的な特徵を比較するために各々の高
さで流れ方向に検查線を想定し，その検查線上の流速 の鋁直成分を時空間プロットした，検査線の長さは，各 栈粗度の中央間の距離に等しくしている. Ls10のケース を対象として得られた時空間分布図を図-8に示寸。この 時空間プロットでは鉛直流速成分の正の成分のみを抽出 して示してある。この図より，LESによる解析でもPIV とよく似た時空間プロットが得られていることがわかる. 特に, 間欠的に発生する強い上昇流の成分が検查線の長 さ(図の横軸長さ)に渡ってほぼ一定の速度で移流してい る点が特徴的である. 一方, 上昇流の出現位置について は，PIV，LESとも栈粗度間で発生(赤い部分)している ケースが多いように見受けられる. 上昇流の発生頻度に ついても，LESはPIVの傾向をある程度捉えている. 寸 なわち，比較的短い間隔でいくつかの上昇流がまとまっ て発生した後, 多少の時間をおいて再び発生するような 二重構造が見られる. これらの点に関しては今後のさら なる検討が必要である.

\section{（5）LESIよる三次元流れ場の可視化}

ここでは, LESで得られた結果を用いて流れの構造につ いて検討寸る. 図-9は, 上から水面における瞬間的な表面 流速ベクトルと水面における発散值の分布, 速度勾配テン ソルの第二普遍量(白色)と流れ方向成分の高速領域(赤色) 
および低速領域(青色)を合成したもの, そして速度勾配テ ンソルの第2普遍量(白色)と強い上昇流の領域(赤色)およ

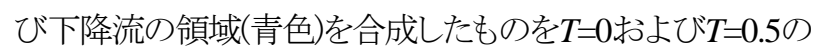
時刻で示す.ただし, このときの表面流速べクトルは, 水面 での発散の様子をとらえやすいように平均流速で動く移動 座標系から見たベクトル $u_{s}\left(=u-U_{m}\right), v_{s}(=v)$ で示す. 速度勾 配テンソルの第二普遍量 $Q$ のプロットでは, $Q=10$ の等值面 を描画しているが, これは三次元的な剥離渦の領域にほぼ 対応する. 図-9に示したのは, その剥離渦が水面にまで達 している瞬間を捉えたものである.ここで，まず注目す ベき点は速度 $u$ 成分の低速領域と渦のある領域がほぼ一 致している点，さらにはこの領域が速度 $v の$ 高速領域つ まり上昇流の発生している領域とも一致している点であ る.このことは, 運動量の低い剥離渦が底面からの強い 上昇流により水面近くまで巻き上げられていることを示 唆している. 図-9に示したよりも前の瞬間の三次元プ ロットなどを調べてみると，これらの上昇流は特に栈粗 度後部の再付着点付近から発生している様子が確認でき た. 次に上流側の栈粗度に着目すると, 時間の経過と共 に上流側から高速流体が底面に吹き付けられている様子 が確認できる.アニメーション化した3次元プロットな どからは，その瞬間に栈粗度間に存在する低速流体が押 し上げられて上昇流となり浮上する状況が多く見られた. 一方，剥離渦が水面に達した付近の水表面では強い正の 発散值が見られる. これはベクトルプロットからも確認 できる．このことから，水表面で見られる湧出しが底面 付近で発生した剥離渦の上昇とその水面への衝突によっ て発生していること， あるいは衝突直前の剥離渦は斜め 上方に傾いた軸を有していることなどがわかる．また， $T=0.5$ においては水面での高発散域は流下とともに減衰 している様子をとらえている。

\section{5. あとがき}

本研究では河床底面で発生する剥離渦が水面変動に及 ぼす影響について基本的な特性を調べるために，単純化 した粗面である栈粗度を対象として実験および数值解析 による検討を行った. その結果, LESによる解析は実験 值をうまく説明できることを示した，ただ，実験では二 次元平面におけるデータしか得られないために, 内部構 造についてはLESの結果を用いた検討を行った。今後は， 境界埋め込み法の特徵をさらに生かすためにさらに複雑 な底面形状で，水面変動が顕著となる高フルード数の流 れ場を対象として実験的, 解析的検討を進める予定であ る.
謝辞 : 本研究は，平成17,18年度科学研究費補助金（基 盤研究 $(\mathrm{C})$, 「河床・河岸の状態が二次元水面変動パ ターンに及ぼす影響に関する研究」, 研究代表者 : 藤田 一郎, 課題番号 : 17560459）の援助のもとに行われた.

\section{参考文献}

1) Jahne, B. and Haußecker, H.: Air water gas exchange, Ann. Rev. Fluid Mech., Vol.30, pp.443-468, 1998.

2) 角野ら : 水表面での気体輸送に関する研究の最新の動向, 土木学会論文集, No.656/II-52, pp.269-287, 2000.

3) 藤田一郎, 河村三郎 : ビデオ画像解析による河川表面流 計測の試み，水工学論文集, Vol.38, pp.733-738, 1994.

4) 藤田一郎他 : ITV施設を利用した河川流の画像計測, 河川 技術論文集，Vol.8,pp.459-464, 2002.

5) 藤田一郎，椿涼太 : 時空間画像を利用した河川表面波紋 の移流速度計測，河川技術論文集，Vol.9,pp.55-60, 2003.

6) Scardovelli, R. and Zaleski, S.: Direct numerical simulation of free-surface and interfacial flow, Ann. Rev. Fluid Mech., Vol.31, pp.567-603, 1999.

7) Shen, L. and Yue, D. K. P.: Large-eddy simulation of freesurface turbulence, J. Fluid Mech. ,Vol.440, pp.75-116, 2001.

8) Ikeda, T. and Durbin, P.A.: Direct simulations of a rough-wall channel flow, Report No.TF-81, Flow Physics and Combustion Division, Stanford University, 2002.

9) Xiaohui, S. and Li, C.W.,: Large eddy simulation of free surface turbulent flow in partly vegetated open channels, International Journal for Numerical Methods in Fluids, Vol.39, pp.919-937, 2002.

10) Peskin,C.S.,: Numerical analysis of blood flow in the heart, Journal of Computational Physics.,25,pp.220-252,1997.

11) Fadln,E.,A., Verzicco,R., Orlandi,P. and Mohd-Yusof,J.: Combined Immersed-Boundary Finite-Difference Methods for Three-Dimensional Complex Flow Simulations, Journal of Computational Physics, 161-1,pp.35-60,2000.

12) Germano, M., Piomelli, U., Moin, P. and Cabot, W. H.,: A dynamic subgrid-scale eddy viscosity model, Phys. Fluids, A3, 7 , pp. 1760-1765,1991.

13）稲垣昌英, 近藤継男, 長野靖尚 : 実用的なLESのための混 合時間スケールSGSモデル, 日本機会学会論文集, B68, 673, pp.2572-2579, 2002.

14）梶島岳夫 : 対流項の差分形式とその保存性, 日本機械学 会論文集, B60, 574, pp.2058-2063, 1994.

15) 東京大学熱流体工学研究室 http://www.thtlab.t.u-tokyo.ac.jp/

(2006. 9. 30受付) 